\title{
INFLUÊNCIA DO ACABAMENTO SUPERFICIAL NA RESISTÊNCIA A OXIDAÇÃO DE AÇOS INOXIDÁVEIS*
}

\author{
Francisco Geraldo Toledo Junior ${ }^{1}$ \\ Geovane Martins Castro ${ }^{2}$ \\ Tarcísio Reis de Oliveira ${ }^{3}$
}

\section{Resumo}

Os aços inoxidáveis possuem características essenciais para um bom acabamento quando o que se busca é estética e boa resistência à oxidação. $O$ acabamento polido é muito utilizado em utensílios domésticos, eletrodomésticos e ponteiras de escapamentos de veículos. Em muitos casos são expostos à elevação de temperatura sendo sujeitos à oxidação a quente que pode causar o amarelamento da superfície desses aços. Através de ensaios de oxidação a quente, potencial eletroquímico, microdureza e tensão residual via difração de raios-x foi possível perceber uma diferença entre os acabamentos brilhantes via laminador com cilindros polidos e acabamentos obtidos pelo polimento de rebolos de panos e pastas abrasivas. O ensaio de tensão residual mostrou qualitativamente que o aumento de dureza e o forte amarelamento ocorrido no material com acabamento polido pode ser em função de uma deformação elástica na superfície imposta durante o processo na linha de polimento automático.

Palavras-chave: Amarelamento; Acabamento; Tensão residual.

\section{INFLUENCE OF SURFACE FINISH ON RESISTANCE TO RUST OF STAINLESS} STEEL

\begin{abstract}
Stainless steels have essential features for a good finish when what is sought is aesthetic and good oxidation resistance. The polished finish is widely used in household items, appliances and tips exhausts of vehicles who in many cases are exposed to high temperature shall be subject to the hot oxidation that can cause the yellowing of the surface of these steels. By heat oxidation testing, electrochemical potential, hardness and residual stress day diffraction $x$-ray was possible to notice a difference between the bright finishes saw mill with polished cylinders and finishes obtained by the wheels of polishing cloths and abrasive slurries. The residual stress test showed qualitatively that the increase in hardness and strong yellowing occurred in the material with polished finish can be due to elastic deformation imposed on the surface during the process in the automatic polishing line.
\end{abstract}

Keywords: Yellowing; Finish; Residual stress.

1 Graduando em Engenharia Metalúrgica, Aluno de Iniciação Científica, Centro Universitário do Leste de Minas Gerais - UNILESTE, Coronel Fabriciano, Minas Gerais, Brasil.

2 Engenheiro, Mestre e Doutorando em Engenharia Metalúrgica, Pesquisador da APERAM, Timóteo, Minas Gerais, Brasil.

3 Engenheiro, Mestre e Doutor em Engenharia Metalúrgica, Pesquisador na APERAM, Timóteo, Minas Gerais, Brasil. 


\section{INTRODUÇÃO}

Em 1912 o inglês Harry Brearly ao realizar algumas análises metalográficas quando estudava uma liga $\mathrm{Fe}-\mathrm{Cr}(13 \%)$, observou que ela resistia ao ataque químico de vários reagentes utilizados em metalografia. Por esse motivo ele identificou esta liga, chamando-a de "stainless steel" que significa "aço que não mancha" e a tradução "inoxidável" que significa isento de óxidos ou não oxidável, o que não é sempre uma verdade.

O uso dos aços inoxidáveis tem crescido atualmente por possuir diferentes propriedades e aplicações. As mais importantes entre elas são sem dúvida a excelente resistência à oxidação em diversos meios onde outros materiais falham, propriedades mecânicas que permitem uma gama variada de projetos e uma aparência superficial excelente que nos permite aplicá-los em projetos onde o apelo a estética se torna primordial.

Existem tipos diferenciados de acabamentos de aços inoxidáveis para as mais diversas aplicações. A tabela abaixo (Tabela 1) mostra alguns dos acabamentos mais utilizados atualmente.

Tabela 1. Tipos de acabamento superficial dos aços inoxidáveis

\begin{tabular}{|c|c|c|}
\hline Tipo & Descrição & Aparência \\
\hline ASTM 480 2B & $\begin{array}{l}\text { Produto laminado a frio, recozido, decapado } \\
\text { e processado no laminador de encruamento } \\
\text { com cilindro brilhante }\end{array}$ & $\begin{array}{l}\text { Superfície com muito } \\
\text { brilho. }\end{array}$ \\
\hline $\begin{array}{l}\text { ASTM } 480 \mathrm{~N}^{\circ} 4 \\
\text { (“Lixado" na } \\
\text { Aperam) }\end{array}$ & $\begin{array}{l}\text { Produto laminado a frio, recozido, decapado, } \\
\text { com lixamento final em uma face e } \\
\text { rugosidade de } 0,15 \text { a } 0,40 \mu \mathrm{m} \mathrm{Ra} \text {. }\end{array}$ & $\begin{array}{l}\text { Superfície escovada e } \\
\text { fosca. }\end{array}$ \\
\hline $\begin{array}{l}\text { ASTM } 480 \text { BB } \\
\text { ("Polido" na } \\
\text { Aperam) }\end{array}$ & $\begin{array}{l}\text { BUFFING BRIGH: Produto laminado a frio, } \\
\text { recozido, decapado, processado no } \\
\text { laminador de encruamento com cilindro } \\
\text { brilhante e com polimento final em uma face. }\end{array}$ & $\begin{array}{l}\text { Superfície com maior } \\
\text { brilho. }\end{array}$ \\
\hline $\begin{array}{l}\text { ASTM } 480 \text { RO } \\
\text { (“IL” na } \\
\text { Aperam) }\end{array}$ & $\begin{array}{l}\text { ROLLED ON: Produto laminado a frio, } \\
\text { recozido e decapado, processado no } \\
\text { laminador de encruamento com cilindro } \\
\text { rugoso em duas faces e rugosidade de } 0,35 \\
\text { a } 0,80 \mu \mathrm{m} \text { Ra. }\end{array}$ & $\begin{array}{l}\text { Superfície escc } \\
\text { com brilho. }\end{array}$ \\
\hline
\end{tabular}

\subsection{Revisão da Literatura}

A reação de oxidação resulta, de fato, na transferência de elétrons do elemento redutor para os níveis eletrônicos livres do elemento oxidante, gerando ganho de oxigênio, perda de elétrons e aumento algébrico do número de oxidação. Pode-se ver claramente que os metais devido ao deslocamento de elétrons, são particularmente apropriados para formar óxidos e é assim que são encontrados na natureza na maioria dos casos [1].

Em temperaturas elevadas a oxidação dos aços inoxidáveis se dá através de mecanismos difusionais nas sucessivas camadas de óxidos formados nas superfícies dos mesmos. O conhecimento destes mecanismos auxilia no estudo da cinética de oxidação dos aços [1].

Os metais apresentam diferentes propensões à corrosão. Como o processo de ionização de um metal cria um potencial elétrico, denominado potencial de eletrodo ou potencial eletroquímico, a propensão à corrosão pode ser avaliada por este potencial. Os potenciais de eletrodo são medidos em relação ao hidrogênio. O 
potencial de eletrodo depende também (além do metal) da natureza e da concentração da solução em que o metal está imerso [2].

O desenvolvimento do penetrador de Knoop pelo National Bureau of Standards USA. e a introdução do dinamômetro de Tukon para o controle da aplicação de cargas menores tornaram os testes de microdureza um procedimento de rotina de laboratório. Esse fato é particularmente útil quando se mede a dureza de uma camada fina (tal como numa camada de revestimento galvânico). A baixa carga usada nos testes de microdureza requer um cuidado extremo em todos os estágios do ensaio [3].

Quando uma peça policristalina de metal é deformada elasticamente, os espaçamentos entre os planos da estrutura dos grãos constituintes mudam o seu valor em relação as distancias sem tensão para algum novo valor correspondente à magnitude da tensão aplicada, sendo este novo espaçamento essencial para se obter o valor da tensão residual no material caso exista [4].

De uma maneira geral, as propriedades fortemente dependentes da microestrutura são determinadas pela quantidade, tamanho, forma e distribuição das fases e dos defeitos cristalinos [2].

Para tanto, esse trabalho tem como objetivo fazer uma análise comparativa da resistência à oxidação de alguns aços inoxidáveis e acabamentos superficiais.

\section{MATERIAIS E MÉTODOS}

As análises foram feitas no Centro de Pesquisas da Aperam - Unidade de Timóteo/MG utilizando amostras de alguns aços inoxidáveis ferríticos e austeníticos oriundas do processo produtivo, conforme tabela abaixo (Tabela 2):

Tabela 2. Normatização e composição Química dos aços utilizados

\begin{tabular}{|c|c|c|c|c|c|c|c|c|c|c|}
\hline \multicolumn{3}{|c|}{ Aço e Normatização } & \multicolumn{8}{|c|}{ Composição Química } \\
\hline Aperam & Internacional & Família & $\begin{array}{l}C \\
(\%)\end{array}$ & $\begin{array}{l}\mathrm{Cr} \\
(\%)\end{array}$ & $\begin{array}{l}\mathrm{Ni} \\
(\%)\end{array}$ & $\begin{array}{l}\mathrm{Nb} \\
(\%)\end{array}$ & $\begin{array}{c}\mathrm{Ti} \\
(\%)\end{array}$ & $\begin{array}{l}\mathrm{Cu} \\
(\%)\end{array}$ & $\begin{array}{c}\mathrm{N} \\
(\mathrm{ppm})\end{array}$ & $\mathrm{Fe}(\%)$ \\
\hline $304 \mathrm{~A}$ & \multirow{2}{*}{ ASTM AISI 304} & \multirow{2}{*}{ Austenítico } & 0,04 & 18,2 & 8,0 & -- & -- & -- & 500 & \multirow{5}{*}{ Balanço } \\
\hline $304 N$ & & & 0,04 & 18,2 & 8,0 & -- & -- & 1,6 & 320 & \\
\hline $430 \mathrm{~A}$ & \multirow{2}{*}{ ASTM AISI 430} & \multirow{3}{*}{ Ferrítico } & 0,05 & 16,2 & -- & -- & -- & -- & 500 & \\
\hline $430 \mathrm{~F}$ & & & 0,02 & 16,2 & -- & 0,4 & -- & -- & 220 & \\
\hline 439 & $\begin{array}{c}\text { ASTM UNS S43035 } \\
\text { type } 439\end{array}$ & & 0,01 & 17,2 & -- & 0,2 & 0,2 & -- & 120 & \\
\hline
\end{tabular}

Fonte: Aperam, 2014

A metodologia da análise e a caracterização das amostras foram divididas em: ensaio de oxidação a baixas temperaturas, medição do potencial eletroquímico, ensaio de microdureza, ensaio de tensão residual via difração de raios-x e microscopia ótica de superfície e microestrutura longitudinal.

As amostras utilizadas estão descritas na tabela abaixo (Tabela 3).

Tabela 3. Amostras utilizadas com dimensões de $50 \times 80 \mathrm{~mm}$

\begin{tabular}{cccc}
\hline Aço & Acabamento & Espessura (mm) & UM \\
\hline $304 \mathrm{~A}\left(^{*}\right)$ & BB (Polido) & 0,8 & $460885 \mathrm{G} 8400 \mathrm{~B}$ \\
\hline $304 \mathrm{~N}$ & BB (Polido) & 0,6 & $461133 \mathrm{~A} 8200 \mathrm{~B}$ \\
\hline $430 \mathrm{~A}$ & 2B & 0,6 & $401860 \mathrm{~B} 9200 \mathrm{~B}$ \\
\hline $430 \mathrm{~A}$ & BB (Polido) & 0,6 & $401860 \mathrm{~B} 9200 \mathrm{~B}$ \\
\hline $430 \mathrm{~F}$ & 2B & 0,6 & $305091 \mathrm{~A} 4000 \mathrm{~B}$ \\
\hline $439 \mathrm{~A}$ & 2B & 0,5 & $400886 \mathrm{H} 9200 \mathrm{~B}$ \\
\hline $439 \mathrm{~A}$ & BB (Polido) & 0,5 & $400886 \mathrm{H} 9200 \mathrm{~B}$ \\
\hline
\end{tabular}

(*) Foram utilizados dois passes na linha de polimento automático. 
Os testes de oxidação foram feitos em forno mufla (marca Vulcan, modelo 3-550) com atmosfera controlada de ar comprimido para garantir suprimento constante de oxigênio que é essencial para oxidação do material. As condições de tempo e temperatura utilizadas são:

- Condição 1: Tempo de 30 min e temperaturas de $200^{\circ}$ e $240^{\circ} \mathrm{C}$;

- Condição 2: Tempo de 3 horas e temperaturas de $160^{\circ}, 180^{\circ}, 200^{\circ}, 220^{\circ} \mathrm{e}$ $240^{\circ} \mathrm{C}$;

- Condição 3: Tempo de 24 horas e temperaturas de $200^{\circ}, 220^{\circ}$ e $240^{\circ} \mathrm{C}$.

Os testes de medição do potencial eletroquímico foram realizados utilizando-se de multímetro, eletrodo de referência de calomelano (ECS) conectado na porta COM e eletrodo de trabalho na porta V.

As amostras tiveram todas as bordas isoladas com fita adesiva de alto aderência e medido continuidade de corrente com o uso de multímetro para certificar total isolação.

Os testes foram realizados utilizando como eletrólito água potável apenas com as amostras antes do teste de oxidação à baixa temperatura e em ambas as faces devido diferença de acabamento nas mesmas. O tempo de imersão foi de 5 minutos. A Figura 1 mostra o esquema de montagem das amostras.

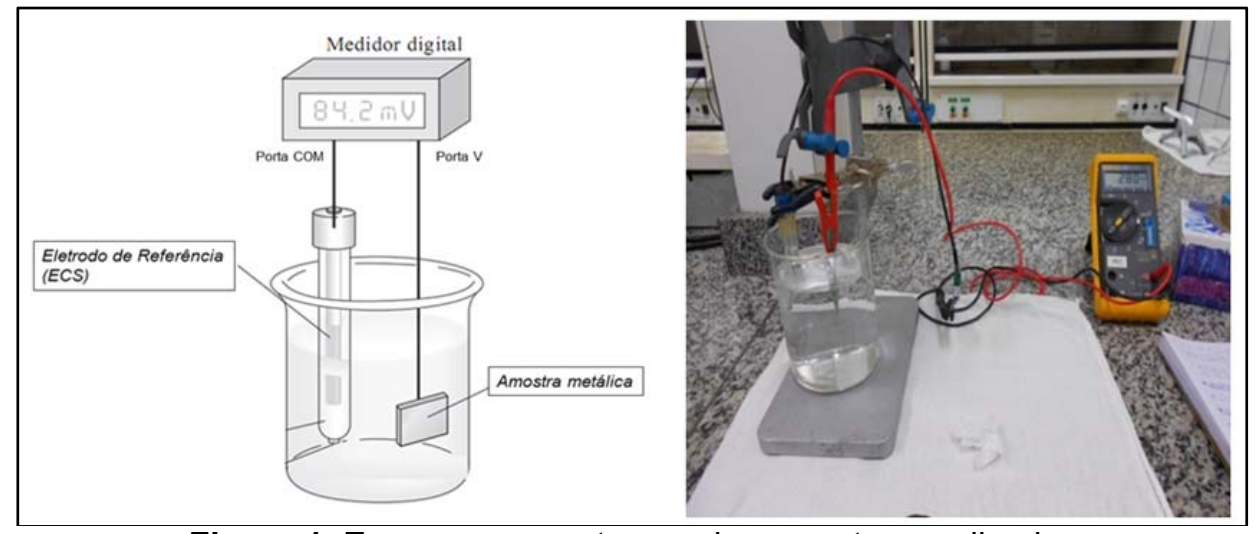

Figura 1. Esquema e montagem das amostras realizada.

Os testes de microdureza forma realizados utilizando-se de microdurômetro de marca Leitz Wetzar. As cargas utilizadas foram de $50 \mathrm{~g}$.

Foram realizadas 10 identações nas amostras antes e após os testes de oxidação e em ambas as faces devido diferença de acabamento nas mesmas.

Os testes de tensão residual foram realizados utilizando o Difratômetro de Raio-X $(\mathrm{DRX})$ de marca Toshiba através do método de Sen $\Psi^{2}$. Utilizou-se o tubo de cobre, sendo os ângulos de difração $2 \theta=137^{\circ}$ para aços ferríticos (CCC e plano 222) e $2 \theta=$ $146^{\circ}$ para aços austeníticos (CFC e plano 331). Dentre todas as radiações, a Cu Ka é geralmente a mais útil. Entretanto, ela causa radiação fluorescente do ferro na amostra. Sendo assim os resultados obtidos serão apenas qualitativos, e não quantitativos.

Os testes foram realizados nas amostras antes dos testes de oxidação em ambas as faces devido diferença de acabamento nas mesmas.

Foram realizadas análises de superfície e microestrutura em ambas as faces devido diferença de acabamento nas mesmas, tanto antes quanto após os testes de oxidação. 


\section{RESULTADOS E DISCUSSÃO}

\subsection{Testes de Oxidação}

As amostras foram caracterizadas antes e após ao teste de oxidação a baixas temperaturas através da medição de amarelamento $(\mathrm{Ye})$ medido pelo espectrofotômetro Byk Gardner - Modelo Spectro-Guide Sphere. O amarelamento (Ye) é definido como sendo a absorção da parte azul do espectro de cores. Geralmente o amarelamento está relacionado com a degradação do material devido a agentes naturais e ou a temperatura.

As Figuras 2 a 5 mostram os resultados do amarelamento em função do tempo e temperatura para os diferentes tipos de aços e acabamentos ensaiados.

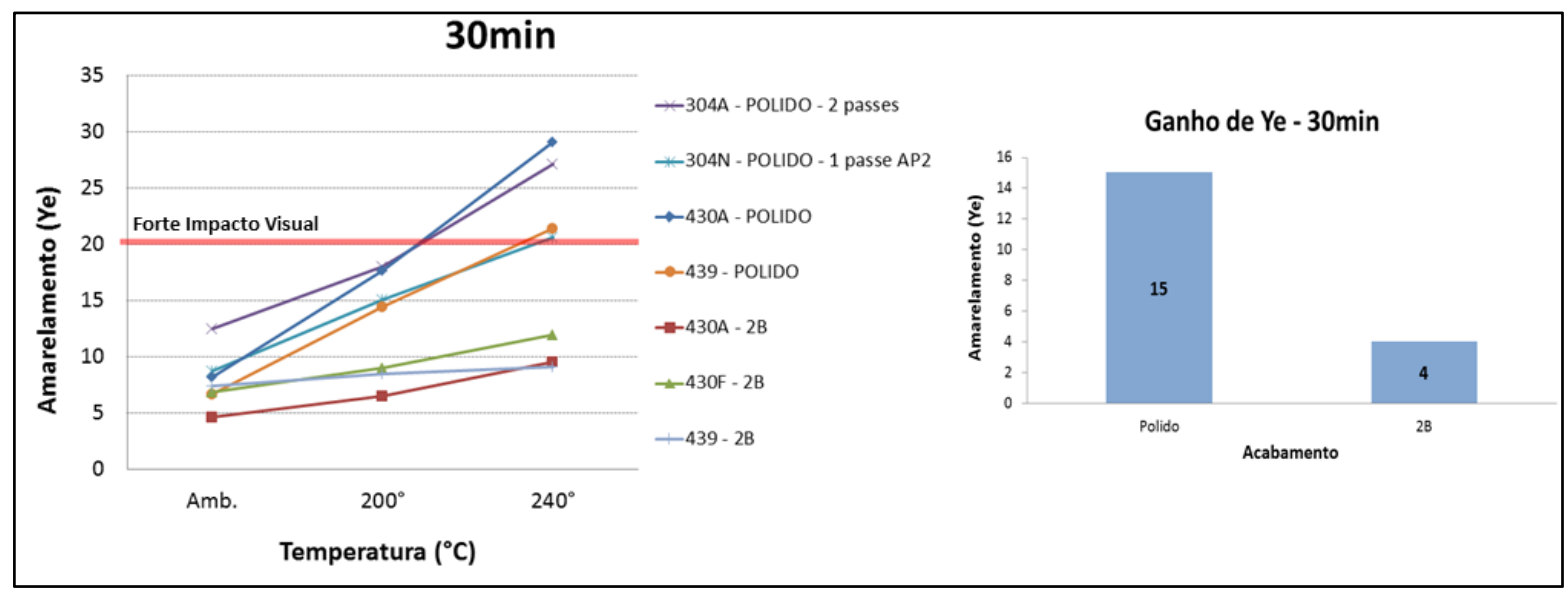

Figura 2. Variação do amarelamento (tempo $x$ temperatura) e o ganho médio de Ye para todos os aços em função do acabamento na condição 1.

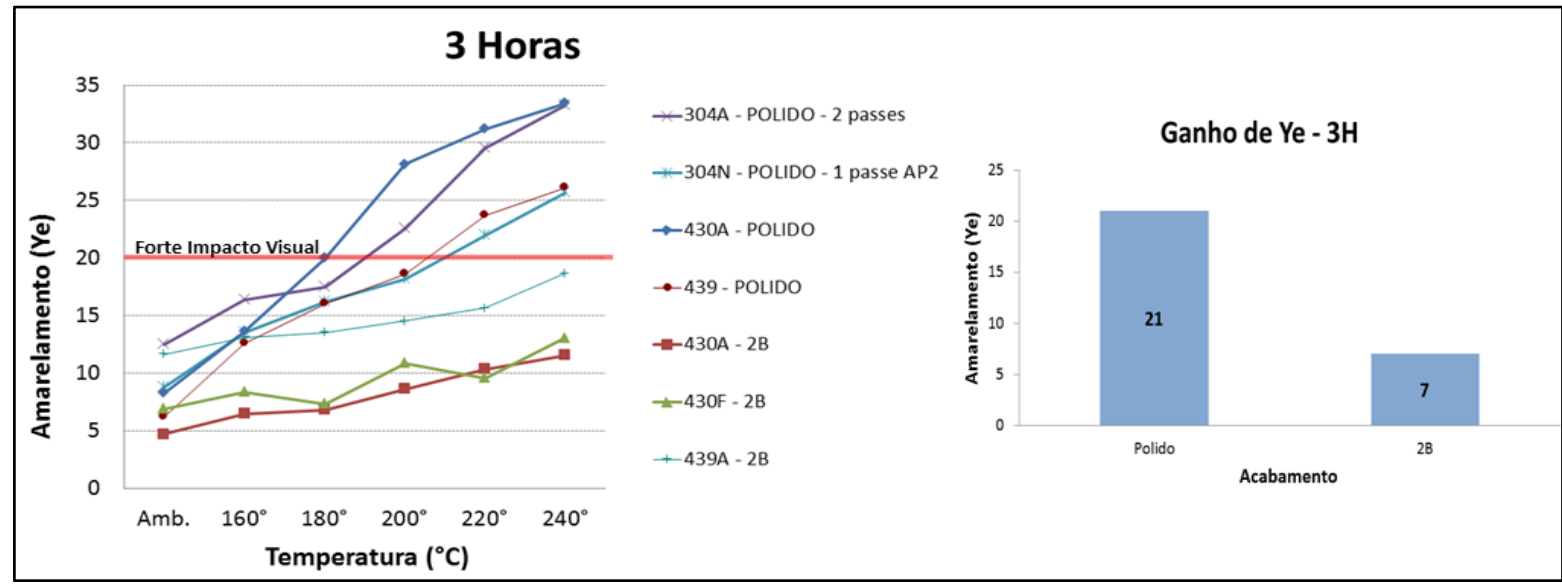

Figura 3. Variação do amarelamento (tempo x temperatura) e o ganho médio de Ye para todos os aços em função do acabamento na condição 2 . 

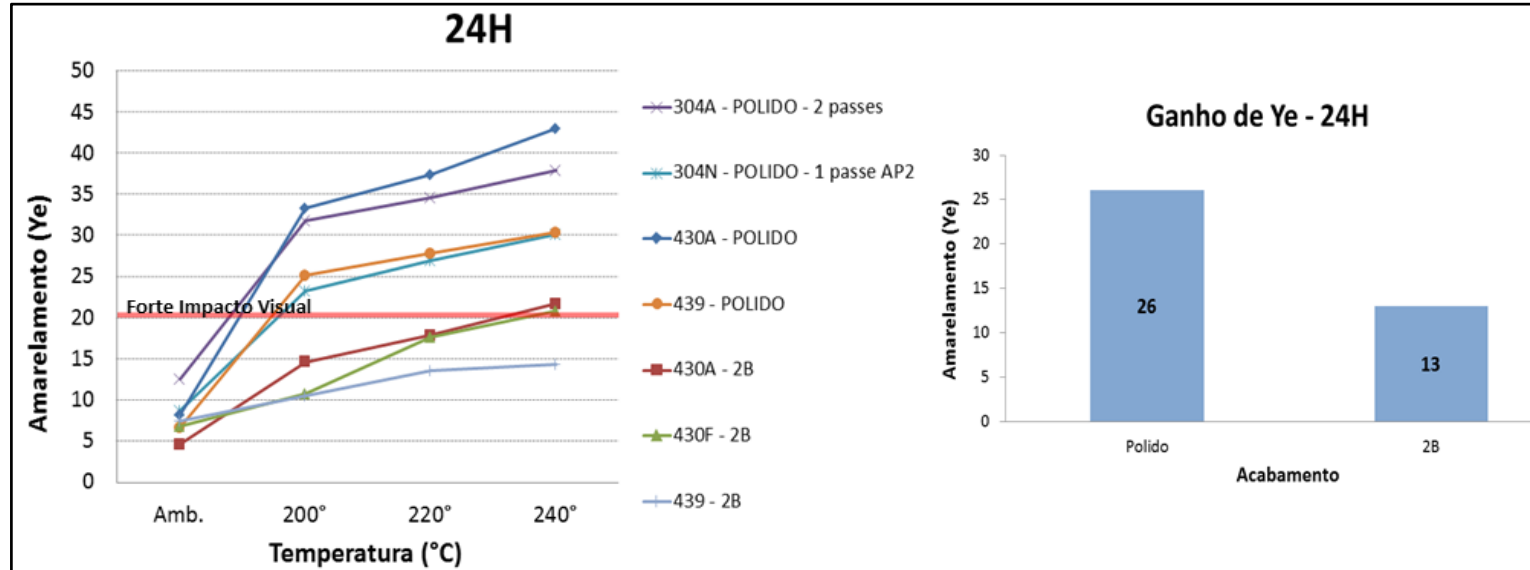

Figura 4. Variação do amarelamento (tempo $x$ temperatura) e o ganho médio de Ye para todos os aços em função do acabamento na condição 3 .

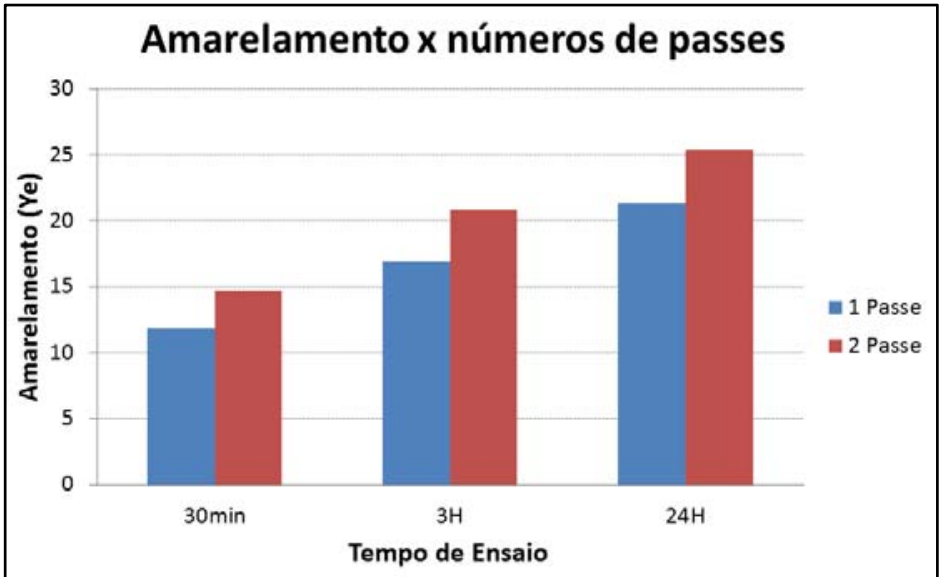

Figura 5. Relação do amarelamento pelo número de passes para os aços 304A (2 passes) e 304N (1 passe).

Verifica-se um aumento discreto do amarelamento para o acabamento $2 \mathrm{~B}$ nos aços ensaiados, mostrando esse acabamento como superior em todos os aços.

Verifica-se um aumento considerável do amarelamento para o acabamento BB (polido) em todos os aços. Pode-se perceber facilmente e visualmente a oxidação da superfície quando o índice de amarelamento (Ye) atinge o valor "20".

No acabamento BB (polido) os aços 439 e 304N (1 passe na linha de polimento automática) se mostraram superiores, seguidos dos 304A (2 passes na linha de polimento) e o aço 430A. O ganho médio de Ye em todos os ensaios mostra que o aumento de amarelamento é em função do acabamento superficial e não do tipo de aço.

Em relação a influência do número de passes, observa-se um maior amarelamento quando o material é submetido a um segundo processamento na linha de polimento, porém a diferença não é tão significativa.

O maior amarelamento na superfície dos materiais com acabamento BB pode ocorrer devido a presença de uma deformação imposta na superfície dos materiais em função do processo produtivo.

\subsection{Testes de Potencial Eletroquímico}

As amostras foram caracterizadas de forma qualitativa usando como eletrólito água potável sendo que quanto mais positivo, mais nobre se mostra a superfície 
analisada. A figura abaixo (Figura 6) mostra o gráfico comparativo dos aços analisados em função do acabamento.

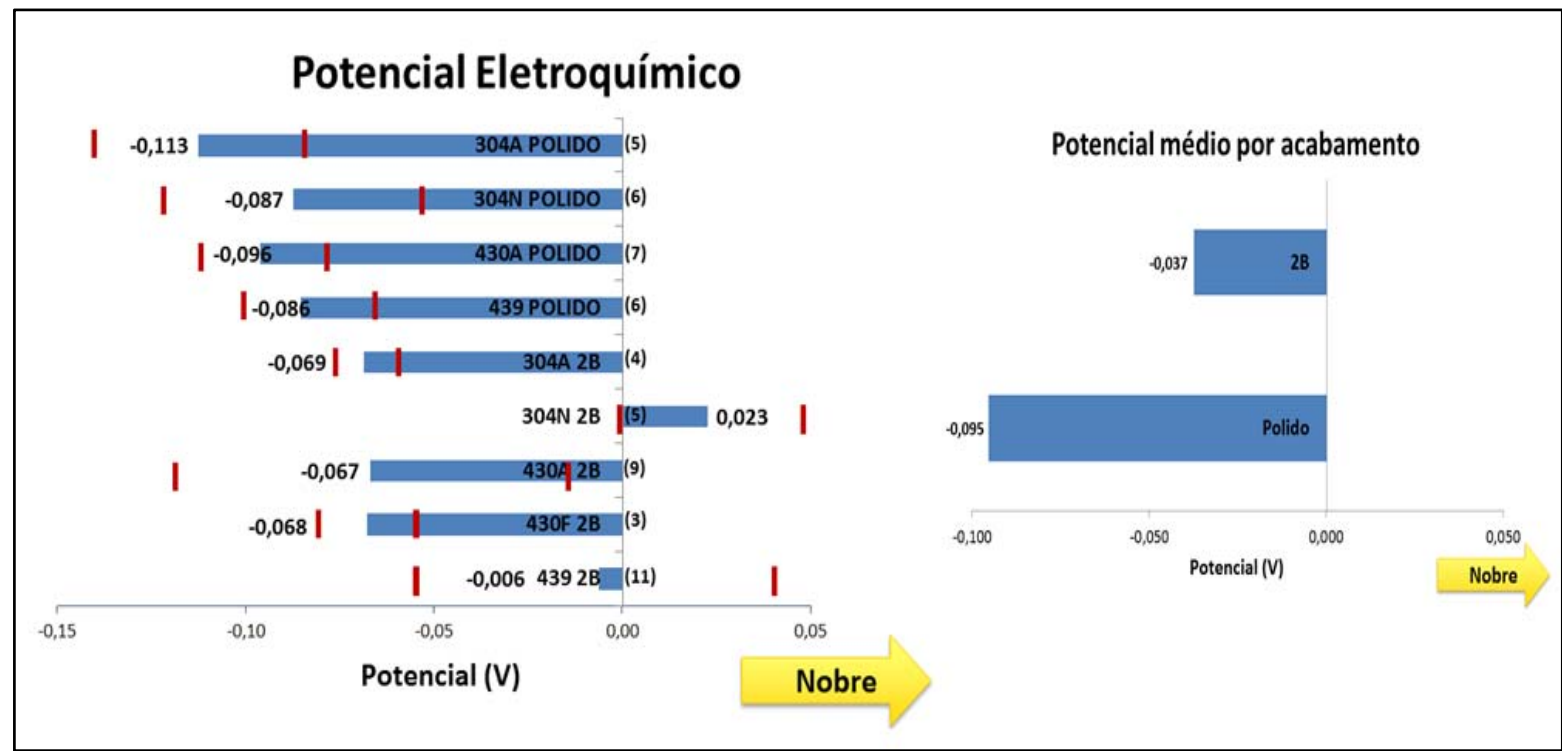

Figura 6. Potencial eletroquímico em função do acabamento.

No ensaio de potencial eletroquímico pode-se notar que os materiais com acabamento BB (polido) se mostraram menos nobre que os materiais com acabamentos 2B. Caso esses materiais sejam colocados ligados na forma de pilhas, o metal mais negativo sofrerá oxidação, enquanto que o mais positivo sofrerá redução.

\subsection{Testes de Microdureza}

Foram realizados 10 identações utilizando de carga de $50 \mathrm{~g}$ em cada face das amostras tanto antes quanto após o teste de oxidação a baixas temperaturas. Os resultados são mostrados nas figuras abaixo (Figuras 7 ).

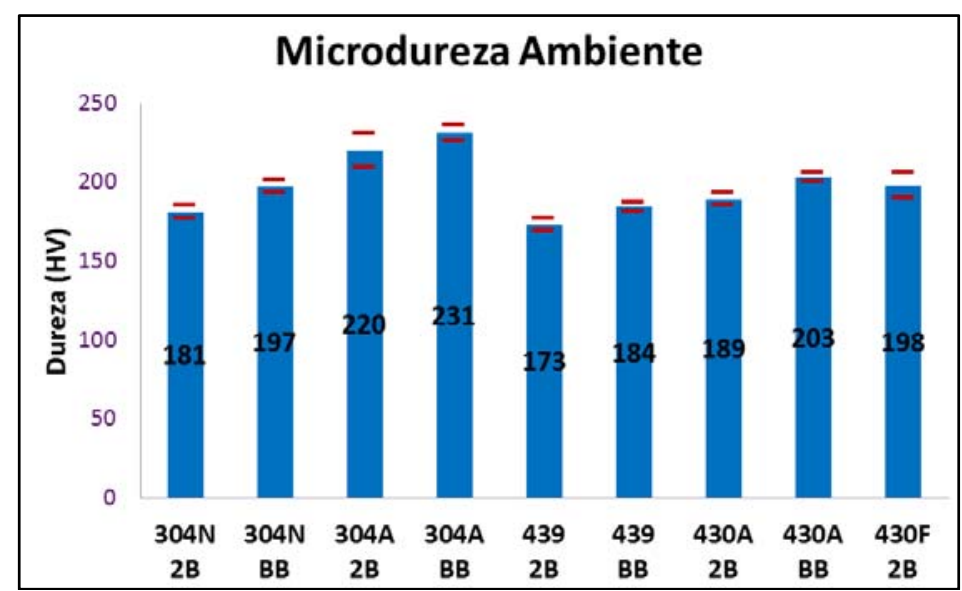

Figura 7. Microdureza média dos aços em função do acabamento.

Os resultados mostraram que a microdureza na face com acabamento BB (polido) se difere da face 2B. A alteração da dureza na superfície pode ser ocasionada em função de uma deformação ou tensão residual imposta na superfície dos materiais durante o processo na linha de polimento automético. 
Outros ensaios mostraram que a identação para o uso da carga de $50 \mathrm{~g}$ na superfície é em torno de $2,5 \mu \mathrm{m}$, ou seja a dureza está sendo medida nos grão da superfície.

\subsection{Testes de Tensão Residual}

Após a coleta de dados pelo difratômetro de raios-x, os dados foram tratados utilizando-se do software X'Pert Stress. Os resultados mostrados nas figuras abaixo (Figura 8 e 9) são de caráter qualitativo em função do tubo utilizado ser de cobre.

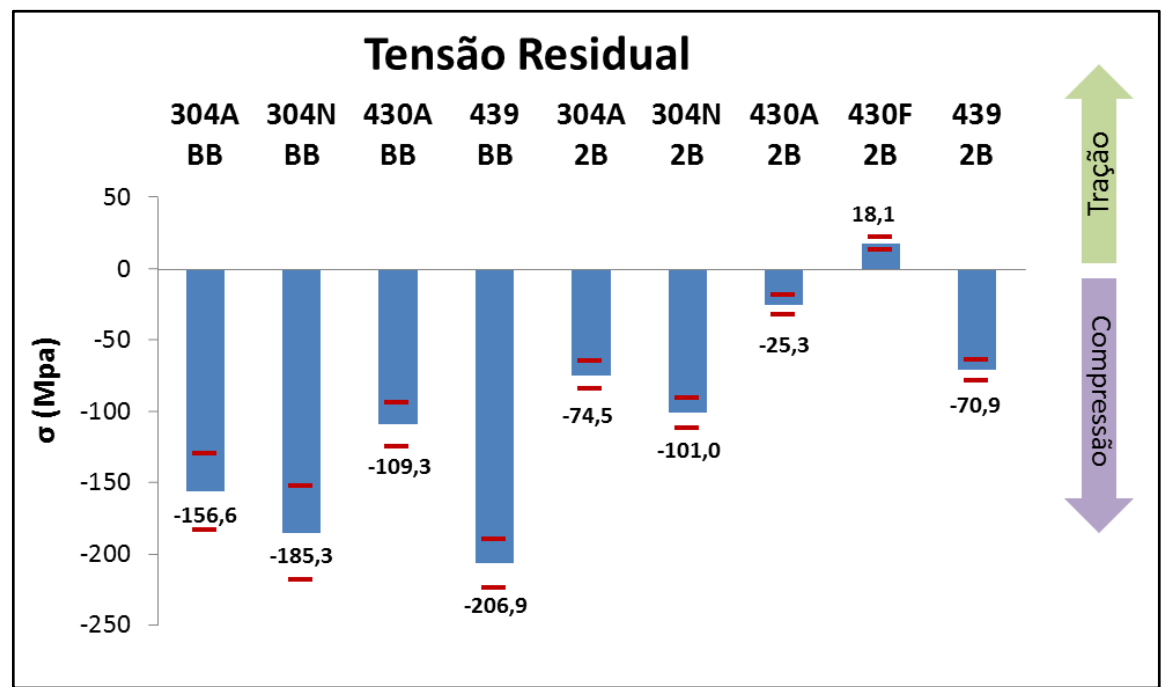

Figura 8. Tensão residual nos aços com acabamentos 2B e BB.

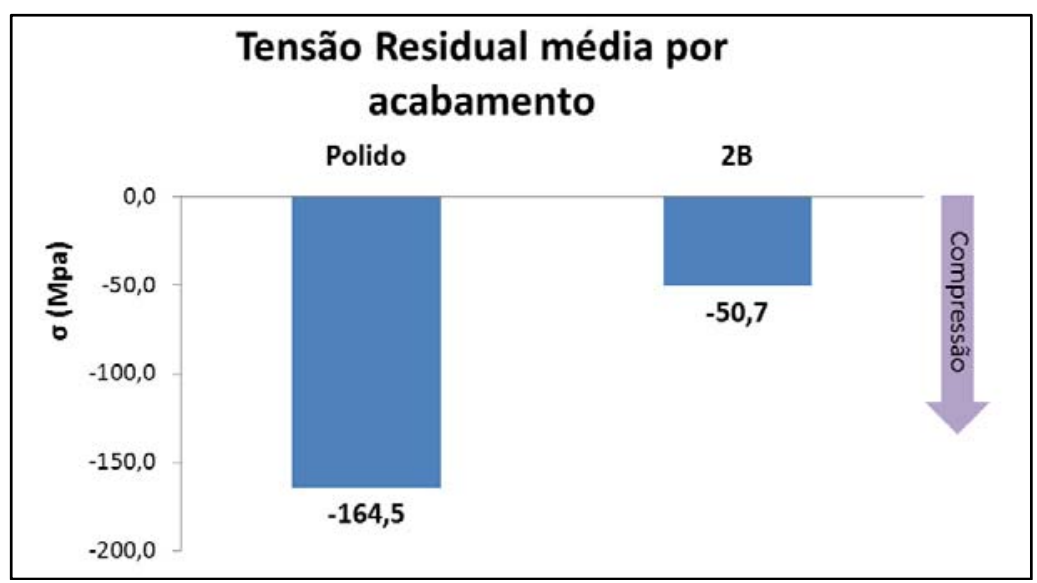

Figura 9. Tensão residual media por acabamentos.

Os valores de tensão com sinais negativos indicam que são tensões de compressão e os de sinais positivos indicam que são de tração.

Das amostras ensaiadas apenas o aço 430F com acabamento 2B indicou tensão de tração. Os demais materiais indicaram tensão de compressão em ambos os acabamentos (2B e BB). As tensões de compressão já eram esperadas nesses acabamentos em função do processo final dos mesmos, sendo o acabamento $2 \mathrm{~B}$ finalizado com um passe de encruamento e o acabamento BB (polido) finalizado via processo de polimento por rolos.

Os acabamentos BB (polido) se mostraram com tensão residual de compressão superior ao acabamento 2B. Mesmo sendo qualitativamente, o aço 439 BB se destacou com maior tensão de compressão em função da quantidade de cabeçotes de polimento ser maior que os demais materiais. 
O aço 304A que teve 2 passes de polimento no acabamento não demonstrou aumento significativo de tensão em relação ao 304N que teve apenas 1 passe.

O caso do aço 430F apresentar tensão de tração, necessita repetir o ensaio e verificar as condições de processos em relação aos demais materiais.

A penetração do feixe de elétrons nesse ensaio em função do ângulo de incidência fica em torno de $10 \mu \mathrm{m}$, ou seja, a tensão está sendo medida nos grãos da superfície.

\subsection{Microscopia Ótica}

No ensaio de microscopia ótica não foi possível visualizar diferenças morfológicas entre os grãos das superfícies com diferentes acabamentos.

\section{CONCLUSÃO}

Os testes de oxidação a baixa temperatura mostraram que o acabamento $2 \mathrm{~B}$ se mostrou superior ao acabamento BB.

$\mathrm{O}$ ensaio de potencial eletroquímico mostrou que o acabamento $2 \mathrm{~B}$ tende a ser mais nobre que o BB. Mas que de uma forma geral as diferenças observadas tendem a não ser relevantes.

O ensaio de microdureza mostrou um leve aumento quando o material passa por um processo de polimento;

O ensaio de tensão residual mostrou que o aumento de dureza e o forte amarelamento ocorrido no material com acabamento BB (polido) é função de uma deformação elástica na superfície imposta durante o processo na linha de polimento. Essa deformação aumenta a energia interna próxima à superfície que ativa com mais facilidade os mecanismos de oxidação e corrosão. Esse mecanismo tende a ser relevante e interfere na resistência a oxidação nos casos estudados.

\section{Sugestão para trabalhos futuros}

Continuidade dos estudos com outros aços e acabamentos, tais como ASTM 480 No4 ("Lixado" na Aperam), ASTM 480 RO ("IL" na Aperam) e Satin Finish.

\section{Agradecimentos}

Agradeço a Aperam South América pelo financiamento da bolsa de iniciação científica e a liberação para o uso dos equipamentos do Centro de Pesquisas na unidade de Timóteo - MG no ano de 2014.

Agradeço ao Centro Universitário do Leste de Minas Gerais - UNILESTE pela oportunidade de realizar esse trabalho em parceria com a Aperam South America.

\section{REFERÊNCIAS}

1 Castro GM. Estudo da oxidação a quente no aço inoxidável ferríticos ABNT 430 [tese de mestrado]. Belo Horizonte: Universidade Federal de Minas Gerais; 2005.

2 Padilha AF. Materiais de engenharia. Curitiba: Hemus Livraria, distribuidora e editora S.A.; 2000.

3 Dieter GE. Metalurgia Mecânica. $2^{a}$ edição. Rio de Janeiro: Guanabara Dois; 1988.

4 Cullity BD. Elements of x-ray diffraction. $2^{\text {nd }}$ Edition. Philippines: Addison-Wesley Publishing Company Inc; 1978. 